\title{
Aggregation of soil clay particles by organic polyelectrolytes
}

Lasareva E.V. ${ }^{1}$, Parfenova A.M. ${ }^{1}$, Azovtseva N.A. ${ }^{2}$

${ }^{1}$ Lomonosov Moscow State University, Chemical Faculty, Moscow, Russia, parf@colloid.chem.msu.ru

${ }^{2}$ Dokuchaev Soil Science Institute, RAS, Moscow, Russia

Keywords: chitosan, humic substances, clay, flocculation, soil structure

doi: 10.36291/HIT.2019.lasareva.036

The aggregation of soil clay particles is the basis of soil structure formation. However, mechanisms of that aggregation are still debatable. Our approach is that combine action of two types of soil organic polyelectrolytes (PE) - labile ones released by soil biota in situ and highly transformed organic PE (Humic substances (HS)) may be responsible for such aggregation. Labile polyelectrolyte (in our experiment it is chitosan) behaves as a flocculant linking mineral particles modified by HS. To confirm our hypothesis turbidimetric and rheological studies of model clays (montmorillonite and kaolinite) and carbonate systems modified with HS were carried out. It was shown, that the modification of clay by humic acid does not affect rheological behavior of their pastes but the strength of such systems enhanced considerably after the interaction of modified clay with a flocculant.

The action of polyelectrolyte mixture has a synergetic effect on the aggregation. Synergism of PE action is explained by the structure of mixed PE layers on the surface of clay particles. The strongly adsorbing cationic polymer (flocculant) having a big number of contacts with the surface of clay particles, forms a thin layer due to charge neutralization and decreases the electrostatic repulsion between particles. They can approach to closer distances that favors the "bridging” flocculation via extended macrochains of anionic polymer (HS) located on the surface. Adsorption of phenols with one, two and three hydroxyl groups that may be incorporated in the HS structure was measured on different soil minerals. It was shown that increasing number of phenolic hydroxyl groups leads to the increase of phenol adsorption on minerals. Clays were found to be better phenol sorbents compared with carbonate and different micas (biotite, muscovite and vermiculite). The modification of montmorillonite with glucose increases adsorption of all phenols.

The proposed adsorption-flocculation mechanism of soil formation due to combine action of different types of organic polyelectrolytes may be applied to other fields of investigation, for instance, the study of aggregation of colloid and particulate riverine matter in the mixing zone river-sea (delta, estuary) where settled aggregates may be a beginning of soil formation [1], water purification and preparation of sand-clay pastes for various applications.

Acknowledgements. The work was supported by the grant RFNP (project № AAAAA16-116030250108-3).

References

1. Lasareva E.V. et al. // Geophysical Research: Biogeosciences. 2019. 124:1-14. https://doi.org/10.1029/2019JG005026. 